\title{
Study on The Effectiveness of Egg Tray and Coir Fibre as A Sound Absorber
}

\author{
Masiri Kaamin ${ }^{1 *}$, Nor Farah Atiqah Ahmad ${ }^{1}$, Norhayati Ngadiman ${ }^{1}$, Aslila Abdul Kadir ${ }^{1}$, \\ Siti Nooraiin Mohd Razali ${ }^{1}$, Mardiha Mokhtar ${ }^{1}$, and Suhaila Sahat ${ }^{1}$ \\ ${ }^{1}$ Centre for Diploma Studies, Universiti Tun Hussein Onn Malaysia, Batu Pahat, Johor, Malaysia.
}

\begin{abstract}
Sound or noise pollution has become one major issues to the community especially those who lived in the urban areas. It does affect the activity of human life. This excessive noise is mainly caused by machines, traffic, motor vehicles and also any unwanted sounds that coming from outside and even from the inside of the building. Such as a loud music. Therefore, the installation of sound absorption panel is one way to reduce the noise pollution inside a building. The selected material must be a porous and hollow in order to absorb high frequency sound. This study was conducted to evaluate the potential of egg tray and coir fibre as a sound absorption panel. The coir fibre has a good coefficient value which make it suitable as a sound absorption material and can replace the traditional material; syntactic and wooden material. The combination of pyramid shape of egg tray can provide a large surface for uniform sound reflection. This study was conducted by using a panel with size $1 \mathrm{mx} 1 \mathrm{~m}$ with a thickness of $6 \mathrm{~mm}$. This panel consist of egg tray layer, coir fibre layer and a fabric as a wrapping for the aesthetic value. Room reverberation test has been carried to find the loss of reverberation time (RT). Result shows that, a reverberation time reading is on low frequency, which is $125 \mathrm{~Hz}$ to $1600 \mathrm{~Hz}$. Within these frequencies, this panel can shorten the reverberation time of $5.63 \mathrm{~s}$ to $3.60 \mathrm{~s}$. Hence, from this study, it can be concluded that the selected materials have the potential as a good sound absorption panel. The comparison is made with the previous research that used egg tray and kapok as a sound absorption panel.
\end{abstract}

\section{Introduction}

Noise also known as the unwanted sound has been recognized as part of environmental nuisance. A person can face progressive loss of hearing with an increase in the threshold of hearing sensitivity due to the continuous exposed to the noise that is $86-90 \mathrm{dBA}$ over a lifetime in industrial settings [1]. Excessive noise can cause the negative effects such as hearing impair, sleep disturbance, communication interface and health effect $[2,3]$. In recent years, the demand for noise barrier has increased due to its importance as part of noise pollution control management.

\footnotetext{
*Corresponding author: masiri@uthm.edu.my
} 
Along with the development of technology, noise control management has become one of the major requirements to improve the quality of living environment. One of the best methods that can control to reduce these unwanted sounds is by using sounds absorption material. The best practice applied is to install sound absorption panels at desirable area. A sound absorption panel has been installed at certain part in the building to reduce the sound level. However, sound absorption panels that are available in the market nowadays used fiberglass as their primary material [4], which has negative impact not only towards the environment but to the human health as well. Although synthetic fibres sound absorption panels performed well, it is costly and not sustainable [5]. These days, natural fibre materials from agricultural such as coconut, rice husk, coir fibre and oil palm frond fibre have widely used as a substitute to synthetic fibres and wood-based material for acoustic absorption purpose [6]. Hence, researchers are more interested in reviewing the application of wood [7], rice straw [8], rice husk [9], wheat straw [10], and bamboo [11] as absorption panels' materials. These sustainable materials are easy to obtain and safe to be use in the environment. This study was conducted by emphasis the characteristics of coir fibre that potentially be a good sound absorber. The coir fibre, which has porous and hollow space, has the ability to absorb the sounds well.

The orientation of sound-absorbing material plays an important role in the effectiveness as a sound absorber. Effect of geometric orientation in the rate of sound absorption has been investigated based on the triangular orientation, semi-circular, rectangular and plate [12]. Result shows that the triangle or pyramid structure can be a good sound absorber for high frequency. This type of structure can be seen on the surface of egg tray and indirectly become the main factor of material selections for this study. The egg tray structure is capable to absorb and reflect the sound waves [13]. Hence, the objective of this study is to identify the characteristics of sound absorption panel based on the natural and recycling materials, which are egg tray and coir fibre as a sound absorbing panel. This study was focused on the use of environmentally sound absorption panel in the reverberation room with a low frequency such as classroom and lecture hall.

\section{Sound Absorption Panels}

All construction materials have acoustic criteria where it does absorb, rebound or transmit sound. Generally, acoustic materials are designed to be used for sound absorption. In acoustic architecture and manual prepared by the manufacturers, these commercial acoustic materials are characterized by sound absorption coefficient where the mean value is taken at $250 \mathrm{~Hz}, 500 \mathrm{~Hz}, 1000 \mathrm{~Hz}$ and $2000 \mathrm{~Hz}$ frequency. These values are useful in comparing the overall absorption level of commercial acoustic materials for reducing sound level.

This study focused on effectiveness characteristic of coir fibre as natural fibre sound absorption panels based on its porous composition. According to [2], an excellent sound absorption coefficient at low frequency is when the room is covered with hollow plats. The increasing of the absorption coefficient can be done by increase the surface density of the materials and increase the airflow obstacles.

The material orientation for sound absorption panels also plays an important role to ensure its effectiveness. A study on the effect of the materials orientation has been done by [12] that based on basic orientation such as triangle, hemisphere, rectangular and plate and the result concluded triangle/pyramid orientation gives the best absorption for high level frequency. This pyramid orientation can be seen and easily obtained from egg cartons. As supported by [13], the orientation of egg cartons is capable of dispersing and rebound sound wave. 


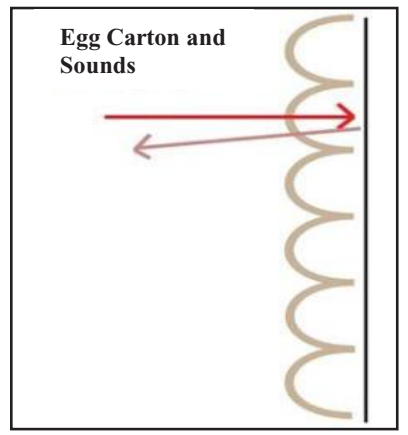

Fig. 1. Sound Wave when hit the egg tray surface [13].

\section{Methodology}

Fig. 2 shows the main materials used for this study; coir fibre, egg cartons, plywood. The combination of these materials helped in strengthening and improving sound absorption characteristics.

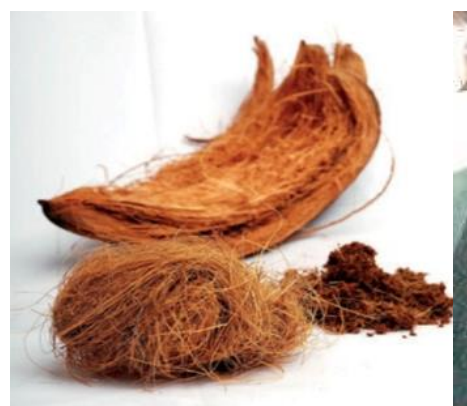

(a)

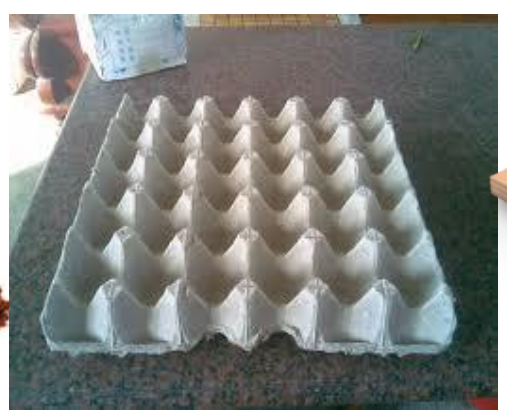

(b)

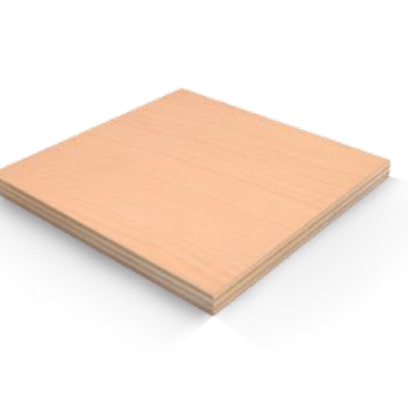

(c)

Fig. 2. Basic Materials for sound absorption panels; (a) Coir fibre, (b) Egg cartons, (c) Plywood.

\subsection{Panels Fabrication}

An impedance tests were carried out to determine the sound absorption coefficient (SAC) before both design could be made. For the fabrication of the composite egg-carton cores, the plywood was used. The design of the panel is illustrated as in Fig. 3. By using stapler gun, each of egg-carton cores were then filled with coir fibre before it been wrapped by black cloth as a layer of finishing for the panels. 


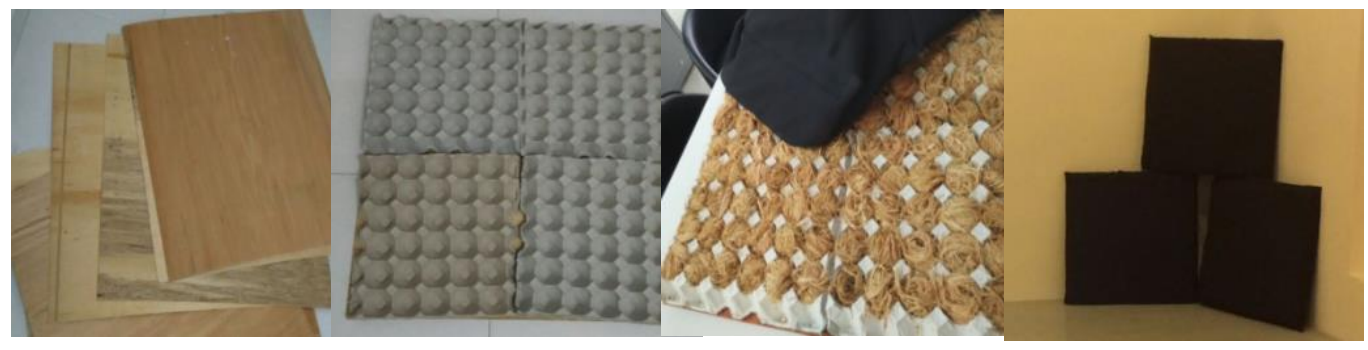

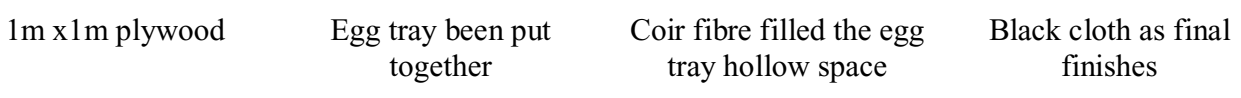

Fig. 3. Absorption Panels Design Stage.

Thirteen panels were made for the study and were hanging in a room with dimensions as described in Fig. 4. According to [14], the testing room must be filled at least 15 to 20 percent with the absorption panels. Due to that, $15 \%$ of the corresponding testing room were filled with absorption panels. The characteristics of the design panels are listed in Table 1.

Table 1. Details sound absorption panels

\begin{tabular}{|c|c|c|}
\hline Parameter & Unit & Panels \\
\hline Structure & - & Sound Absorption Panel \\
\hline Material & - & Egg-carton and coir fibre \\
\hline Thickness & $\mathrm{mm}$ & 45.0 \\
\hline Density & $\mathrm{kg} / \mathrm{m}^{3}$ & 0.42 \\
\hline Area & $\mathrm{m}^{2}$ & 0.0036 \\
\hline
\end{tabular}

\subsection{Reverberant Field Method}

Fig. 4 shows the equipment setup for the tests and layout of the echo chamber located at Acoustic Laboratory, FKAAS, UTHM. This room was designed represented a real situation to investigate maximum effect of noise from various angles. Absorption panels have been tested in echo chamber concedes to the ISO 354 standards. The required parameter that needed is an echo time (seconds) for the empty room and room with the absorption panels. This echo time were collected at two different positions of microphone; Microphone 1 and Microphone 2. 

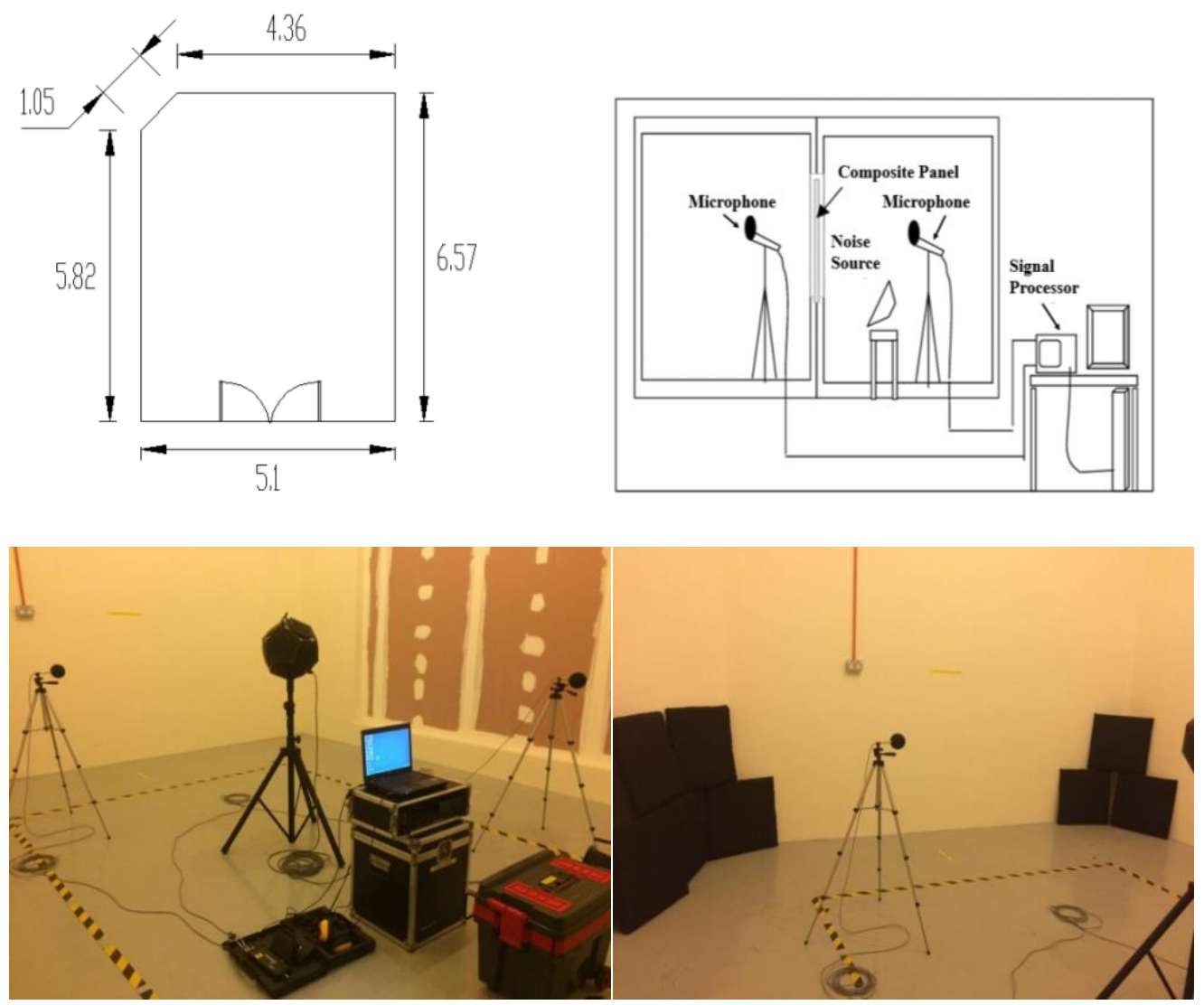

Fig. 4. Equipment setup and layout of the echo chamber.

\section{Results and discussions}

Echo that produced due to the hitting of the sound waves to any obstacles is different depending on the obstacle material. It can be heard in small space with hard walls such as in a cave. But, if these echoes meet a soft surface, the sound wave will be absorbed. In this study, there is difference of echoes time obtained for the room with and without absorption panels. Fig. 5 and Fig. 6 both shows the results for Microphone 1 and Microphone 2 respectively. The result shows an obvious different of echoes time loss at low frequency between $31.5 \mathrm{~Hz}-1600 \mathrm{~Hz}$ compared to high frequency. Generally, the echoes time at both microphones is shorter in a room filled with absorption panel than the empty room. The maximum echoes time loss for the empty room is 5.63s and 5.74s for Microphone 1 and Microphone 2 respectively. While for room filled with absorption panels, the echoes time losses are 3.60s for Microphone 1 and 3.73s for Microphone 2. Due to that matter, it is safe to conclude that this absorption panel that are made from egg-cartons and coir fibre is an excellent absorption panel for low frequency. This can be related with the size of coir fibre itself. As highlighted in [12] study, the fine fibre can increase the coefficient of sound absorption. Since this material used in the original size, this panel is more suitable for low frequency. So, it's proven that agricultural waste is in an absorbing material group [10]. 


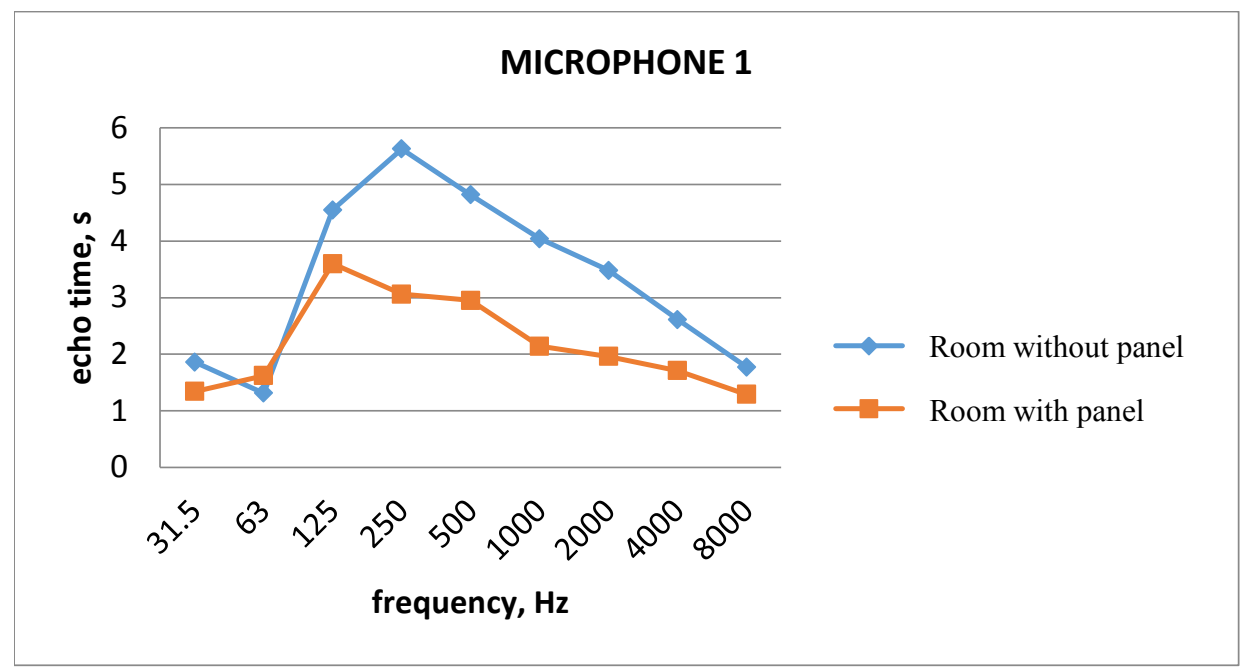

Fig. 5. Echoes time for Microphone 1.

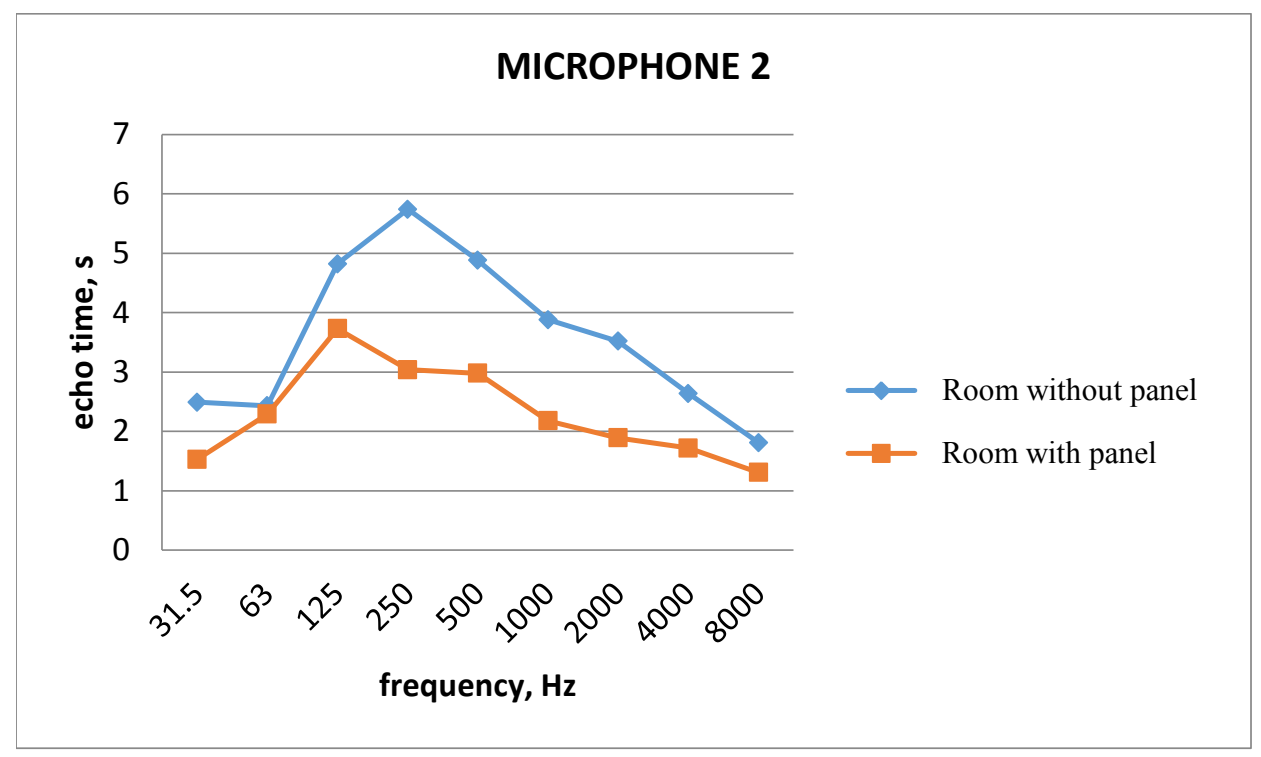

Fig. 6. Echoes time for Microphone 2.

\section{Conclusions}

There are many other ways in utilizing recycled materials like egg-cartons and coir fibre. Stepping up to the challenge, this study has proven that the useable egg-cartons and coir fibre have the criteria of performing an effective sound absorption pane that is more environmental friendly. For future study, other natural fibers can be used to replace the egg-cartons.

Authors would like to extend his gratitude to all participants who helped directly and indirectly in this study. The authors also thanked Office for Research, Innovation, Commercialization and Consultancy 
Management (ORICC), UTHM, Johor for their support and also to Siti Nur Ezianie Mohamad A'Ashri, Suria Fathri Mohd Rethuan and Mai Zatul Amira Mior Ramlee for their efforts.

\section{References}

1. S.A. Stansfeld, M. P. Matheson, British M.B 68 (1), 243-257, (2003)

2. R. Zulkifli, Zulkarnain, M. J. M. Nor, American Journal of Applied Sciences 7 (2), 260-264 (2010)

3. N. Singh, S.C. Devar, J. Hum, Ecol. 16 (3), 181-187 (2004)

4. M. Kaamin, N. S. M. Mahir, A. A. Kadir, N. B. Hamid, M. Mokhtar, N. Ngadiman, Sound absorption study on acoustic panel from kapok fibre and egg tray. AIP Conference Proceedings 1901, 130012 (2017)

5. A. Nick, U. Becker, W.Thoma, Journal of Polymers and The Environment 10 (3),115118, (2002)

6. M.J. M. Nor, N. Jamaluddin, F.M Tamiri, Electronic Journal-Technical Acoustics 3 (8), 1-8 (2004)

7. C. Wassilief, Applied Acoustic 48, 339-356, (2003)

8. H. S. Yang, D. J. Kim, H. J. Kim, Bioresource Technol 86, 117-21 (2003)

9. V. Ajiwe, C.A. Okeke, S.C. Ekwuozor, Uba IC., Bioresource Technol 66, 41-43 (1998)

10. M. Saadatnia, G. Ebrahimi, M. Tajvidi, Proceedings of the $17^{\text {th }}$ World Conference on Nondestructive Testing, 25-28 October 2008, Shanghai, (2008)

11. T. Koizumi, N. Tsujiuchi, A. Adachi, High Performance Structures and Composite Book (WTT Press, Southampton, UK., 2002)

12. Y. E. Lee, W. J. Chen, AUTEX Research Journal 3(2), 78-84 (2003)

13. M. Boughan, Egg Cartons Get Egg on Their Face in Acoustics Test. Para, 3. Retrieved from https://acousticalsolutions.com (2012)

14. F. Simon, J. Pfretzschner, Noise and Vibration Worldwide 35 (1) (2004) 